University of Nebraska - Lincoln

DigitalCommons@University of Nebraska - Lincoln

USDA National Wildlife Research Center - Staff Publications
U.S. Department of Agriculture: Animal and Plant Health Inspection Service

4-30-2002

\title{
Uncertainty of Exploitation Estimates Made from Tag Returns
}

\author{
L.E. Miranda
}

U.S. Geological Survey, Biological Resources Division, Mississippi Cooperative Fish and Wildlife Research Unit

R.E. Brock

U.S. Geological Survey, Biological Resources Division, Mississippi Cooperative Fish and Wildlife Research Unit

B.S. Dorr

U.S. Geological Survey, Biological Resources Division, Mississippi Cooperative Fish and Wildlife Research Unit, brian.s.dorr@aphis.usda.gov

Follow this and additional works at: https://digitalcommons.unl.edu/icwdm_usdanwrc

Part of the Environmental Sciences Commons

Miranda, L.E.; Brock, R.E.; and Dorr, B.S., "Uncertainty of Exploitation Estimates Made from Tag Returns" (2002). USDA National Wildlife Research Center - Staff Publications. 479.

https://digitalcommons.unl.edu/icwdm_usdanwrc/479

This Article is brought to you for free and open access by the U.S. Department of Agriculture: Animal and Plant Health Inspection Service at DigitalCommons@University of Nebraska - Lincoln. It has been accepted for inclusion in USDA National Wildlife Research Center - Staff Publications by an authorized administrator of DigitalCommons@University of Nebraska - Lincoln. 


\title{
Uncertainty of Exploitation Estimates Made from Tag Returns
}

\author{
L. E. Miranda, ${ }^{*}$ R. E. Brock,${ }^{1}$ And B. S. DorR ${ }^{2}$ \\ U.S. Geological Survey, Biological Resources Division, \\ Mississippi Cooperative Fish and Wildlife Research Unit, \\ Post Office Box 9691, Mississippi State, Mississippi 39762, USA
}

\begin{abstract}
Over 6,000 crappies Pomoxis spp. were tagged in five water bodies to estimate exploitation rates by anglers. Exploitation rates were computed as the percentage of tags returned after adjustment for three sources of uncertainty: postrelease mortality due to the tagging process, tag loss, and the reporting rate of tagged fish. Confidence intervals around exploitation rates were estimated by resampling from the probability distributions of tagging mortality, tag loss, and reporting rate. Estimates of exploitation rates ranged from $17 \%$ to $54 \%$ among the five study systems. Uncertainty around estimates of tagging mortality, tag loss, and reporting resulted in $90 \%$ confidence intervals around the median exploitation rate as narrow as 15 percentage points and as broad as 46 percentage points. The greatest source of estimation error was uncertainty about tag reporting. Because the large investments required by tagging and reward operations produce imprecise estimates of the exploitation rate, it may be worth considering other approaches to estimating it or simply circumventing the exploitation question altogether.
\end{abstract}

The exploitation rate of fisheries is often estimated by releasing a known number of tagged fish and determining the proportion harvested by fishers. This seemingly straightforward estimation makes various assumptions including no loss of tags, no death due to the tagging process (tagging mortality), no emigration or immigration of tagged or untagged fish, no recruitment, no differential natural mortality between marked and unmarked fish, full reporting compliance, and equal vulnerability to angling between marked and unmarked fish (Ricker 1975). There are many ways to violate these assumptions and render estimates of exploitation rate unreliable. These sources of error should be carefully reviewed and, if possible, corrected before exploitation rate estimates are applied to management.

Violation of the tagging mortality, tag loss, and tag reporting assumptions are often documented in exploitation surveys. Compliance is sought by estimating the correct departure from these assumptions. Mortality associated with the capture and tagging process is commonly estimated by holding tagged fish in laboratory tanks, culture ponds, or in situ net pens (Pierce and Tomcko 1993; Szedl-

\footnotetext{
* Corresponding author: smiranda@usgs.gov

1 Present address: Texas Parks and Wildlife Department, 6200 Hatchery Road, Fort Worth, Texas 76114, USA.

2 Present address: U.S. Department of Agriculture, Wildlife Research Center, Post Office Box 6099, Mississippi State, Mississippi 39762, USA.
}

Received December 1, 2000; accepted April 30, 2002 mayer and Howe 1995). Mortality estimates are used to lower the number of tagged fish actually available to fishers. Tag loss has been estimated by double-tagging (Muoneke 1992), holding fish for periodic observation (Hale and Gray 1998), or applying a permanent mark for comparison with a temporary mark (Brewin et al. 1995). Estimates of tag loss are used to expand the number of fish returned. Reporting of tagged fish by fishers has been estimated using escalating-value rewards (Nichols et al. 1991), monitoring report of tags observed during creel surveys (Larson et al. 1991), surreptitious tagging during creel surveys (Green et al. 1983), postcards as tag surrogates (Zale and Bain 1994), and preseason and postseason models (Hearn et al. 1998). Estimates of incomplete reporting are used to augment the number of fish returned.

Because tagging mortality, tag loss, and reporting are never known with certainty, corrected exploitation rates have error that propagates with each applied correction. If error is large, exploitation rate estimates may be uninformative, and the expense associated with deriving them may be unjustified. Nevertheless, the uncertainty associated with exploitation rate estimates is seldom measured.

Crappies provide the highest fishery yields in reservoirs of the United States (Miranda 1999). To prevent overexploitation and sustain yields, managers often resort to harvest restrictions such as bag, length, and seasonal limits. The success of harvest restrictions hinges on mortality being mostly due to fishing (Allen and Miranda 1995). 
However, natural and fishing mortality of crappies can be variable in response to cyclicity of crappie populations (Allen and Miranda 1998). Therefore, managers often try to estimate fishing mortality, frequently through tagging (Van den Avyle 1993). We evaluate the uncertainty associated with estimates of fishing mortality of crappies derived through tagging after correcting for tagging mortality, tag loss, and incomplete reporting; we also question whether the effort invested in deriving these estimates is balanced by the reliability of the estimates.

\section{Methods}

\section{Study Sites}

Exploitation rate was estimated at Beulah, Chotard, and Eagle lakes, and Columbus and Sardis reservoirs. Lakes Beulah (in Arkansas and Mississippi; $417 \mathrm{ha}$ ) and Chotard (Louisiana and Mississippi; 405 ha) are oxbows adjacent to the Mississippi River and are connected with the river for several months during high river stages. Eagle Lake (Louisiana and Mississippi; 1,902 ha) is also an oxbow adjacent to the Mississippi River, but it is isolated from the river by the river's levee. At the time of this study, crappie fisheries in these oxbows were regulated with a daily creel limit of 50 fish/angler. Columbus Reservoir (Mississippi; $3,564 \mathrm{ha}$ ) is a navigation reservoir in the Tennessee-Tombigbee Waterway in eastcentral Mississippi; a 23-cm minimum length limit and a daily creel limit of 30 fish/angler were in effect. Sardis Reservoir (Mississippi; 23,675 ha) is a flood control reservoir impounded on the Yazoo River in northcentral Mississippi; a 25-cm minimum length limit and a daily creel limit of 30 fish/angler were in effect.

\section{Fish Tagging}

Crappies were captured by trap-netting and electrofishing in late winter 1993 in Columbus Reservoir, fall 1993 and spring 1994 in Lake Beulah, late winter 1995 in Sardis Reservoir, fall 1995 in Chotard Lake, and late winter and spring 1996 in Eagle Lake. Trap nets had 1.3-cm bar mesh and frame dimensions described by Miranda et al. (1996). Electrofishing was conducted with a 5,000$\mathrm{W}$, boat-mounted AC generator and 200-450-V pulsed DC that was applied with Coffelt's CPS waveform to waters with conductivities ranging from 90 to $240 \mu \mathrm{S} / \mathrm{cm}$. Voltages were adjusted to achieve voltage gradients ranging from 0.1 to $1 \mathrm{~V} /$ $\mathrm{cm}$. Guidelines described by Reynolds (1996) were followed during electrofishing.
Length of the smallest fish tagged was selected based on the minimum length limit in effect at the study site; where there was no length limit, fish of the minimum length considered harvestable by most Mississippi anglers $(20 \mathrm{~cm}$; Miranda and Frese 1991) were tagged. We used a Floy Mark II tagging gun to insert two yellow Floy 65B T-bar anchor tags on their left side of each fish just below the dorsal fin and approximately $1.0-1.5 \mathrm{~cm}$ apart. Tags were inscribed with a reward notice and a return address.

\section{Exploitation Rate Estimates}

Exploitation rates were estimated as the fraction of tags returned by anglers adjusted for tagging mortality, tag loss, and incomplete reporting. Below we describe each adjustment and how its associated variability was applied to estimates of exploitation rate.

Tagging mortality.-The probability of killing a tagged fish as a result of capturing, handling, and tagging was estimated by placing random samples of tagged crappies into $0.80-\mathrm{m}$ diameter, $3.65-\mathrm{m}$ long hoop nets submerged in water 2-3 m deep. About 10-17 fish were placed in each hoop net and held for approximately $48 \mathrm{~h}$ to estimate postrelease mortality. The probability of mortality $\left(P_{m}\right)$ was estimated as the fraction of fish that did not survive the holding period.

Tag loss rate.-Tag loss rate was estimated from the number of tags attached to fish at the time they were recaptured by anglers. The mean of the response variable (i.e., 1 for no tag lost or 0 for a single tag lost) was assumed to be related to time with a logistic model of the form

$$
P_{t}=1-\frac{e^{\left(b_{1} \cdot \log _{e} d+b_{0}\right)}}{1+e^{\left(b_{1} \cdot \log _{e} d+b_{0}\right)}}
$$

where $P_{t}=$ probability of tag loss, $b_{1}=$ parameter estimate, $d=$ number of days between tagging and capture, and $b_{0}=y$-intercept estimate. The probability of loosing both tags was estimated as $P_{t}^{2}$.

Incomplete reporting.-Each tag was inscribed with a reward notice and a return address. Tag returns were encouraged by offering limited-edition caps for each tagged fish reported. Caps were made available in various colors to encourage multiple returns from the same angler. Posters explaining the study, tag-return procedures, and the reward system were placed in prominent locations at boat ramps, tackle shops, and gasoline stations around the water bodies. Postage-paid envelopes were made available at tackle shops near each wa- 
TABLE 1.-Number of fish tagged and reported and exploitation rate estimates for five water bodies where crappie exploitation was examined. Exploitation rates were estimated as the percentage of tags returned after correction for postrelease mortality associated with tagging, tag loss, and reporting of tagged fish. The probabilistic distribution of each exploitation rate was estimated by resampling 1,000 times from the probabilistic distribution of the correction factors.

\begin{tabular}{|c|c|c|c|c|c|c|c|}
\hline \multirow[b]{2}{*}{ Water body } & \multicolumn{2}{|c|}{ Number of fish } & \multicolumn{5}{|c|}{ Exploitation rates $(\%)$ by percentile } \\
\hline & Tagged & Reported & 10 & 25 & 50 & 75 & 90 \\
\hline Beulah Lake & 551 & 38 & 12 & 14 & 17 & 22 & 27 \\
\hline Chotard Lake & 1,389 & 167 & 21 & 24 & 29 & 38 & 46 \\
\hline Columbus Reservoir & 1,602 & 367 & 39 & 44 & 54 & 70 & 85 \\
\hline Eagle Lake & 896 & 185 & 33 & 41 & 49 & 64 & 78 \\
\hline Sardis Reservoir & 1,596 & 319 & 35 & 39 & 48 & 62 & 76 \\
\hline
\end{tabular}

ter body. The research was publicized through articles in local and regional newspapers and television programs.

The probability of a tag being reported $\left(P_{r}\right)$ was estimated with two methods. First, a postcard system described by Zale and Bain (1994) served as surrogate tags to estimate the willingness of anglers to return a tag. Cards $(N=245)$ were distributed to anglers in the study lakes, instructed to check the appropriate responses and mail the card. The card explained the purpose of the survey, posed two questions (irrelevant to our study) about the tagging program that could be answered quickly, and offered as reward the same caps given for tags. Second, during a statewide telephone survey of over 6,000 anglers in 1994 (Schramm and Gill 1995), respondents who acknowledged catching a tagged fish (any tagged fish, not just those tagged during this study) were asked if they had reported the tag.

Exploitation.-Exploitation rate $(\mu)$ was estimated as the fraction of tags returned after correction for postrelease mortality, tag loss, and reporting of tagged fish. Each return $n$ was corrected for tag loss by dividing by the tag retention rate corresponding to the time elapsed between tagging and recapture, summing the corrected returns for the 1-year period since tagging, correcting this sum by reporting rate, and then dividing by the number of tagged fish released $(N)$ after adjusting $N$ for tagging mortality. Thus,

$$
\mu=\frac{\sum\left[n\left(1-P_{t}^{2}\right)^{-1}\right] \cdot P_{r}^{-1}}{N\left(1-P_{m}\right)} .
$$

A probabilistic distribution of exploitation rate values was estimated by resampling 1,000 times from the assumed distribution of the correction factors. Values of $P_{t}$ and $P_{m}$ were selected at random within their $90 \%$ confidence limits, assuming a normal probability distribution; values of $P_{r}$ were selected assuming a uniform probability distribution. The 10th, 25th, 50th (median), 75th, and 90th percentiles of the distribution of $\mu$ were calculated.

\section{Results}

\section{Tagging Summary}

We captured and tagged 6,034 crappies in the five study lakes (Table 1). Lengths of fish tagged were 20.0-39.8 cm. Between March 1993 and May 1997, 1,076 of the tagged crappies were recaptured by anglers in the study lakes and reported (Table 1). Most recaptures (78\%) occurred during MarchJune. The length ranges of crappies recaptured were $20.0-38.8 \mathrm{~cm}$ (i.e., the lengths recorded at tagging).

\section{Tagging Mortality}

In all, 231 crappies were used in 22 trials. The combined numbers of mortalities recorded in all trials was 25. Mean $P_{m}$ for the 22 trials was $11 \%$ $(\mathrm{SE}=7.2 \%, 90 \%$ confidence interval $=0-23.4)$. Water temperature during the trials was $16-24^{\circ} \mathrm{C}$, but no correlation between mortality and temperature was evident within this limited range $(P=$ $0.63)$.

\section{Tag Loss}

The logistic regression model describing the relation between number of days at large and tag loss indicated there was a significant effect of time on tag loss. The probability of losing a tag $\left(P_{t}\right)$ was

$$
P_{t}=1-\frac{e^{\left(-0.496 \log _{e} d+3.04\right)}}{1+e^{\left(-0.496 \log _{e} d+3.04\right)}} .
$$

Standard errors for $b_{1}$ and $b_{0}$ were 0.11 and 0.29 , respectively, which were used to create confidence limits for each $P_{t}$. The logistic model suggests that a small percentage of the tags $(4.6 \%)$ were lost within the first day following release, and that 
nearly half of the tags $(47.2 \%)$ were lost within 1 year.

\section{Reporting}

Of the 245 cards distributed, 59 were returned, all within $30 \mathrm{~d}$, for a reporting rate of $24 \%$. The telephone survey revealed that $64 \%$ of the 249 anglers who acknowledged catching a tagged fish had reported the catch to the address inscribed on the tag (Schramm and Gill 1995). These two values of $P_{r}$ were the only available estimates and were considered to represent the upper and lower range from which the 1,000 values of $P_{r}$ were selected using uniform probability.

\section{Exploitation}

Median exploitation rate in the study lakes was 17-54\% (Table 1). The 10th and 90th percentiles deviated by as little as 15 percentage points (i.e., $12-27 \%$ ) to as much as 46 percentage points (i.e., $39-85 \%)$. The spread in percentiles was greatly influenced by the widely diverging upper and lower $P_{r}$ values. When the divergence in $P_{r}$ values was reduced in half (i.e., from $24-64$ to $34-54$ ), the 10 th and 90th percentiles deviated by as little as 8 percentage points to as much as 23 percentage points over the five water bodies. When reduced to nothing (i.e., $P_{r}$ fixed at 44 and only $P_{m}$ and $P_{t}$ allowed to fluctuate), the 10th and 90th percentiles differed by as little as 3 percentage points to as much as 10 percentage points.

\section{Discussion}

Confidence bands around exploitation rate estimates were generally wide and directly related to level of exploitation rate. If fishery managers needed to be at least $90 \%$ confident that their estimates were within a liberal $20 \%$ of the real $\mu$, they would have failed to achieve this target in all but one lake (Beulah Lake, Table 1). We suggest that $\mu$ values with bands greater than $20 \%$ are not precise enough.

Estimates of tagging mortality and tag loss were not difficult to obtain and had reasonably low error that resulted in estimates of exploitation rate with narrow confidence intervals. Nevertheless, the level of tagging mortality (mean $=11 \%, \mathrm{SE}=7.2$ ) may not be justifiable, particularly given the low reliability of the exploitation rate estimates. Also, estimates of tag loss in the study waters (represented by over 1,000 returns from five water bodies) were perhaps better than average, whereas most studies similar to this one are conducted in a single water body and involve fewer returns, which might produce wider confidence intervals.

In contrast, estimates of reporting were variable and difficult to obtain and represented a major obstacle to estimating exploitation rate through tag returns. The $24 \%$ return of surrogate postcards and $62 \%$ compliance estimated through the telephone survey were similar to estimates made by Maceina et al. (1998) in Alabama, who recorded 27\% return on postcards and an $85 \%$ declaration of compliance when anglers were questioned in person. Our modeling showed that reducing this uncertainty resulted in estimates of exploitation that were more precise. However, estimates of compliance have typically been wide-ranging and untrustworthy. Compliance was $31-61 \%$ in a California reservoir (Rawstron 1971), 18-52\% in an Oregon stream (Moring 1980), 15-36\% in Texas bays (Green et al. 1983), 67-92\% in Missouri reservoirs (Colvin 1991), and $29-71 \%$ in Georgia reservoirs (Larson et al. 1991). Tag reward schemes are typically used to encourage tag reporting. Murphy and Taylor (1991) found no significant differences in rate of return among tags ranging in reward value from US\$5 to $\$ 50$. Jenkins et al. (2000) found return rate was higher for tags labeled "reward" than those labeled "no reward" but no difference between those labeled "reward" and "\$50 reward." Nichols et al. (1991) estimated that return rate neared $100 \%$ as reward values for duck bands approached $\$ 400$. We suspect that response to no- or low-reward tags are unpredictable and that large rewards not only encourage return rate but also make them more predictable. Nevertheless, a costly reward system that will reduce uncertainty about a reporting rate may frequently exceed project budgets.

Exploitation rate estimates made through tag returns are expensive. The major components of such an undertaking include (1) tags, tagging equipment, and operation and maintenance of equipment to collect fish (e.g., nets or electrofishers, boats, vehicles); (2) personnel outlay during tagging (often several weeks) and to administer returns (data recording and replying to anglers for several years after the study is completed); and (3) the cost of the reward program (an unknown until the program is completed). Additional expenditures include obtaining estimates of compliance. Recognizing the impending large investment and the shortcomings of the estimates, fishery managers need to consider other approaches to estimating exploitation rate.

A miscellany of other approaches are available 
to estimate exploitation rate directly or to indirectly signal precarious levels of fishing mortality. One direct approach is to estimate the ratio of fish harvested to population size at the beginning of the season, but difficulties associated with measuring both of these variables render this approach unreliable, except in small populations. Another direct approach involves regression of fishing effort on total annual mortality to estimate natural mortality (intercept of regression), which is then subtracted from the total mortality to yield fishing mortality (Van den Avyle 1993). However, there are several weaknesses associated with this approach. Variations of these basic approaches are described by Ricker (1975) and Quinn and Deriso (1999).

Indirect rapid-assessment methods may be appealing given the multiplicity of shortcomings associated with direct estimation. Individuals in heavily exploited populations may be expected to show increased condition and reproductive output. Populations exposed to high exploitation may be expected to have a low density of adults, high overall mortality, truncated length and age-frequency distributions, reduced longevity, faster growth, and increased recruitment variability (Reed and Rabeni 1989; Toetz et al. 1991; Craig et al. 1995; Allen and Miranda 2001). Communities in which those heavily exploited populations reside might show increased prey and competitor species. From a fishery perspective, excessive exploitation may be reflected in reduced catch rates and increased number of unsuccessful anglers. These are just examples of variables that may be commonly available during routine fishery surveys and may be used alone or in combination to signal excessive exploitation. Although the information provided by these variables is only suggestive, in many cases such measurements may be preferable over measurements derived from expensive and imprecise tagging studies.

Another option is to circumvent estimates of exploitation and work directly with annual mortality. Because size of fish in a population is a function of growth and mortality, populations with large fish are likely to have low mortality, fast growth, or both. When growth is factored out of this relation, there is an inverse relationship between size and mortality, such that excessive mortality produces severe reductions in size. Given this connection and because fish size is a prominent factor in recreational fishery programs, managers could identify size objectives for the population and identify total mortality limits beyond which the size objective cannot be attained (Miranda 2002). Total mortality can then be estimated from catch curves (Ricker 1975) and compared with the mortality limit. Mortality values nearing the limit serve as a warning sign to step up monitoring; mortality values exceeding the limit would require reductions in exploitation that are equal to or larger than the excess annual mortality.

\section{Acknowledgments}

This research was funded by the Mississippi Department of Wildlife, Fisheries and Parks through Sport Fish Restoration funds. We thank M. Allen, K. Cash, L. Isaak and K. Meals for assistance in the field. J. Hightower, B. Hubbard, and S. Raborn provided constructive reviews of the manuscript.

\section{References}

Allen, M. S., and L. E. Miranda. 1995. An evaluation of the potential value of harvest restrictions in managing crappie fisheries. North American Journal of Fisheries Management 15:766-772.

Allen, M. S., and L. E. Miranda. 1998. An age-structured model for erratic crappie fisheries. Ecological Modelling 107:289-303.

Allen, M. S., and L. E. Miranda. 2001. Quasi-cycles in crappie populations are forced by interactions among population characteristics and environment. Canadian Journal of Fisheries and Aquatic Sciences 58:594-601.

Brewin, M. K., L. L. Stebbins, and J. S. Nelson. 1995. Differential losses of floy anchor tags between male and female brown trout. North American Journal of Fisheries Management 15:881-884.

Colvin, M. A. 1991. Population characteristics and angler harvest of white crappies in four large Missouri reservoirs. North American Journal of Fisheries Management 11:572-584.

Craig, J. F., J. A. Babaluk, S. G. Stevenson, and P. C. Williams. 1995. Variation in growth and reproduction of walleye (Stizostedion vitreum) in three Manitoba lakes. Canadian Journal of Zoology 73:367372 .

Green, A. W., G. C. Matlock, and J. E. Weaver. 1983. A method for directly estimating tag-reporting rate of anglers. Transactions of the American Fisheries Society 112:412-415.

Hale, R. S., and J. H. Gray. 1998. Retention and detection of coded wire tags and elastomer tags in trout. North American Journal of Fisheries Management 18:197-201.

Hearn, W. S., K. H. Pollock, and E. N. Brooks. 1998. Pre- and post-season tagging models: estimation of reporting rate and fishing and natural mortality rates. Canadian Journal of Fisheries and Aquatic Sciences 55:199-205.

Jenkins, W. E., M. R. Denson, and T. I. J. Smith. 2000. Determination of angler reporting level for red drum (Sciaenops ocellatus) in a South Carolina estuary. Fisheries Research 44:273-277. 
Larson, S. C., B. Saul, and S. Schleiger. 1991. Exploitation and survival of black crappies in three Georgia reservoirs. North American Journal of Fisheries Management 11:604-613.

Maceina, M. J., P. W. Bettolli, S. D. Finely, and V. J. Dicenzo. 1998. Analyses of the sauger fishery with simulated effects of a minimum size limit in the Tennessee River of Alabama. North American Journal of Fisheries Management 18:66-75.

Miranda, L. E. 1999. A typology of fisheries in large reservoirs of the United States. North American Journal of Fisheries Management 19:536-550.

Miranda, L. E. 2002. Establishing size-based mortality caps. North American Journal of Fisheries Management 22:433-440.

Miranda, L. E., and W. Frese. 1991. Can fishery scientists predict angler preferences? Pages 375-379 in D. Guthrie, J. M. Hoenig, M. Holliday, C. M. Jones, M. J. Mills, S. A. Moberly, K. H. Pollock, and D. R. Talhelm, editors. Creel and angler surveys in fisheries management. American Fisheries Society, Symposium 12, Bethesda, Maryland.

Miranda, L. E., M. S. Schorr, M. S. Allen, and K. O. Meals. 1996. Description of a floating trap net for sampling crappies. North American Journal of Fisheries Management 16:457-460.

Moring, J. R. 1980. Nonreporting of recaptures of tagged rainbow trout from an Oregon stream. Progressive Fish-Culturist 42:113-115.

Muoneke, M. I. 1992. Loss of floy anchor tags from white bass. North American Journal of Fisheries Management 12:819-824.

Murphy, M. D., and R. G. Taylor. 1991. Preliminary study of the effect of reward amount on tag-return rate for red drums in Tampa Bay, Florida. North American Journal of Fisheries Management 11: 471-474.

Nichols, J. D., R. J. Blohm, R. E. Reynolds, R. E. Trost, J. E. Hines, and J. P. Bladen. 1991. Band reporting rates for mallards with reward bands of different dollar values. Journal of Wildlife Management 55: 119-126.
Pierce, R. B., and C. M. Tomcko. 1993. Tag loss and handling mortality for northern pike marked with plastic anchor tags. North American Journal of Fisheries Management 13:613-615.

Quinn, T. J., II, and R. B. Deriso. 1999. Quantitative fish dynamics. Oxford University Press, New York.

Rawstron, R. R. 1971. Nonreporting of tagged white catfish, largemouth bass and bluegills by anglers at Folsom Lake, California. California Fish and Game 57:246-252.

Reed, M. S., and C. F. Rabeni. 1989. Characteristics of an unexploited smallmouth bass population in a Missouri Ozark stream. North American Journal of Fisheries Management 9:420-426.

Reynolds, J. B. 1996. Electrofishing. Pages 221-253 in B. R. Murphy and D. W. Willis, editors. Fisheries techniques, 2nd edition. American Fisheries Society, Bethesda, Maryland.

Ricker, W. E. 1975. Computation and interpretation of biological statistics of fish populations. Fisheries Research Board of Canada Bulletin 191.

Schramm, H. L., Jr., and D. A. Gill. 1995. Measurement of Mississippi angler characteristics. Mississippi Department of Wildlife, Fisheries and Parks, Freshwater Fisheries Report 140, Jackson.

Szedlmayer, S. T., and J. C. Howe. 1995. An evaluation of six marking methods for age-0 red drum, Sciaenops ocellatus. U.S. National Marine Fisheries Service Fishery Bulletin 93:191-195.

Toetz, D., M. Muoneke, and J. Windell. 1991. Age, growth and condition of brook trout (Salvelinus fontinalis) from an unexploited alpine lake. Northwest Science 65:89-92.

Van den Avyle, M. J. 1993. Dynamics of exploited fish populations. Pages 105-135 in C. C. Kohler and W. A. Hubert, editors. Inland fisheries management in North America. American Fisheries Society, Bethesda, Maryland.

Zale, A. V., and M. B. Bain. 1994. Estimating tag-reporting rates with postcards as tag surrogates. North American Journal of Fisheries Management 14: 208-211. 